Journal of Applied Biosciences 146: 15040 - 15045

ISSN 1997-5902

NOTE TECHNIQUE

\title{
Bien cultiver l'arachide et le maïs en rotation
}

\author{
Akanza Kouadjo Paul ${ }^{* 1}$, N'Da Hugues Annicet ${ }^{1}$, Gbakatchetche Henri. Cousin ${ }^{1}$ \\ ${ }^{1}$ Centre National de Recherche Agronomique (CNRA). 01 BP 1740 Abidjan 01 (Côte d'Ivoire). \\ Auteur correspondant : e-mail : paul.akanza@yahoo.com \\ * Original submitted in on 3rd December 2019. Published online at www.m.elewa.org/journals/ on 29th February 2020 \\ https://doi.org/10.35759/JABs.v146.6
}

\section{INTRODUCTION}

La rotation culturale est une technique agricole qui vise le maintien ou l'amélioration de la fertilité des sols et l'augmentation des rendements. L'arachide (Arachis hypogaea L.) est la légumineuse la plus cultivée dans les régions Nord et Centre de la Côte d'Ivoire (Manizan et al., 2018). Sa croissance végétale est dépendante de l'azote et du phosphore (Bado, 2002). Or, la majorité des paysans sont pauvres et dépensent peu pour l'achat des engrais minéraux. Face à cette situation, il est indispensable de promouvoir et soutenir des techniques moins exigeantes en ressources financières. La quasi-totalité de petits exploitants de Côte d'Ivoire pratiquent des systèmes de cultures plurispécifiques comprenant des rotations dont celles de légumineuses à graines avec des céréales. Ces systèmes de culture constituent des moyens importants de gestion de la fertilité du sol. La matière organique fournit par les fanes d'arachide influence diverses caractéristiques chimiques et fonctions du sol. Une production de biomasse permet d'améliorer la couverture et la teneur en matière organique du sol. Cette fiche est un outil d'aide à la construction de rotations qui brisent la monoculture, préservent la fertilité des sols, améliorent les rendements en garantissant la durabilité des systèmes de culture.

\section{CULTURE DE L'ARACHIDE}

\section{Conditions et préparation du sol}

L'arachide se développe mieux dans un sol léger sablo-limoneux à pH faiblement acide (6,0-6,5). Un pH de 5,5 à 7,0 est encore acceptable et certaines variétés locales peuvent s'adapter à un $\mathrm{pH}$ allant jusqu'à 7,8 . Effectuer un labour profond ou léger pour rendre le sol meuble en vue de faciliter la germination des graines et la pénétration des gynophores dans le sol. 


\section{Systèmes de culture et possibilité de diversification}

\section{Rotation culturale}

Les arachides doivent être cultivées selon un système de rotation culturale. L'arachide présente l'avantage de fixer l'azote atmosphérique pour le restituer au sol. La décomposition des fanes de cette légumineuse, riches en éléments minéraux, améliore la qualité des sols. Ainsi la culture de l'arachide enrichit le sol et agit comme le meilleur précédent cultural du maïs.

\section{Matériel végétal}

La rotation arachide/maïs met en jeu deux espèces végétales et donc deux variétés, l'une d'arachide et l'autre de maïs (tableau 1).

Tableau 1 : Caractéristiques principales des variétés en rotation

\begin{tabular}{|c|c|c|c|c|}
\hline Variétés & $\begin{array}{l}\text { Cycle } \\
\text { (j) }\end{array}$ & $\begin{array}{l}\text { Zone de } \\
\text { culture }\end{array}$ & $\begin{array}{l}\text { Rendement } \\
\text { (t.ha-1) }\end{array}$ & Caractéristiques \\
\hline $\begin{array}{c}\text { Maïs } \\
\text { var. EV8728 }\end{array}$ & 90 & $\begin{array}{l}\text { Toute l'étendue du } \\
\text { territoire } \\
\text { national }\end{array}$ & 3 à 5 & $\begin{array}{ll} & \text { Grains de couleur jaune à } \\
\text { texture dentée. } \\
\text { - } \quad \text { Tolérante à la striure et à la } \\
\text { verse }\end{array}$ \\
\hline $\begin{array}{l}\text { Arachide } \\
\text { var. 3-5A }\end{array}$ & 100 & $\begin{array}{l}\text { Toute l'étendue du } \\
\text { territoire } \\
\text { national }\end{array}$ & 2 à 3 & $\begin{array}{ll}\text { - } & \text { Bonne couverture du sol } \\
\text { - } & \text { Biomasse abondante } \\
\text { - } & \text { Lutte contre les mauvaises } \\
& \text { herbes et l'érosion du sol } \\
\text { - } & \text { Amélioration de la fertilité du } \\
& \text { sol }\end{array}$ \\
\hline $\begin{array}{l}\text { Rotation } \\
\text { arachide/maïs }\end{array}$ & - & $\begin{array}{c}\text { Toute l'étendue du } \\
\text { territoire } \\
\text { national }\end{array}$ & & $\begin{array}{l}\text { - Les petits paysans sont les } \\
\text { principaux utilisateurs }\end{array}$ \\
\hline
\end{tabular}

\section{Mise en place}

\section{Choix du terrain}

Le sol doit être suffisamment meuble ou ameubli pour faciliter la germination, la pénétration des gynophores entre 40-70 JAS et l'arrachage des gousses mûres. Les meilleurs sols doivent être bien drainés et aérés. Les sols à texture fine, meubles et perméables, en particulier les sols sableux à sablo-limoneux sont les plus appropriés. Choisir donc un terrain plat ou légèrement en pente. Eviter les sols trop argileux et battants.

Préparation du terrain

Défricher tout en évitant de brûler la biomasse végétale source de fertilité. En culture mécanisée ou attelée : labourer, pulvériser, herser. En culture manuelle, labourer à la daba puis semer. Ne pas apporter de la fumure minérale à l'arachide en vue de la contraindre à satisfaire ses propres besoins d'azote par la fixation biologique.

\section{Semis et densité de semis}

Prévoir $50 \mathrm{~kg}$ de semences d'arachide décortiquée pour 1 ha. Semer à une profondeur de $3 \mathrm{~cm}$ sur un sol humide, au lendemain d'une pluie de $15 \mathrm{~mm}$, quand la saison des pluies s'est bien installée. Dans les régions des savanes du Nord, semer entre mi-juin et mi-juillet de chaque année. Le semis s'effectue en lignes distantes de $50 \mathrm{~cm}$. L'écartement entre poquets de 3 graines sur la ligne est de $20 \mathrm{~cm}$. Après un démariage à 2 plants par poquet, une densité de 200000 plants par hectare, convenable, sera obtenue. A cette densité, il se produit une parfaite couverture du sol par l'arachide ce qui conduit à un travail biologique satisfaisant dans sol (racines, rhizobium) 


\section{Semis de l'arachide}

Dans les zones où le régime pluviométrique présente deux saisons culturales bien prononcées, semer l'arachide en première saison et le maïs en deuxième saison (voir calendrier cultural).

Par contre, dans les régions où le régime pluviométrique est monomodal et ne permet pas de pratiquer deux cycles culturaux dans la même année, effectuer la culture d'arachide en année 1 et celle du maïs en année 2.

\section{Entretien de la culture}

Désherbage chimique

Utiliser en prélevée du Round Up 360 à raison de 3 I.ha-1 au lendemain du semis

Désherbage manuel

Effectuer un ou deux sarclages manuels au besoin. Eviter de sarcler après la fructification.

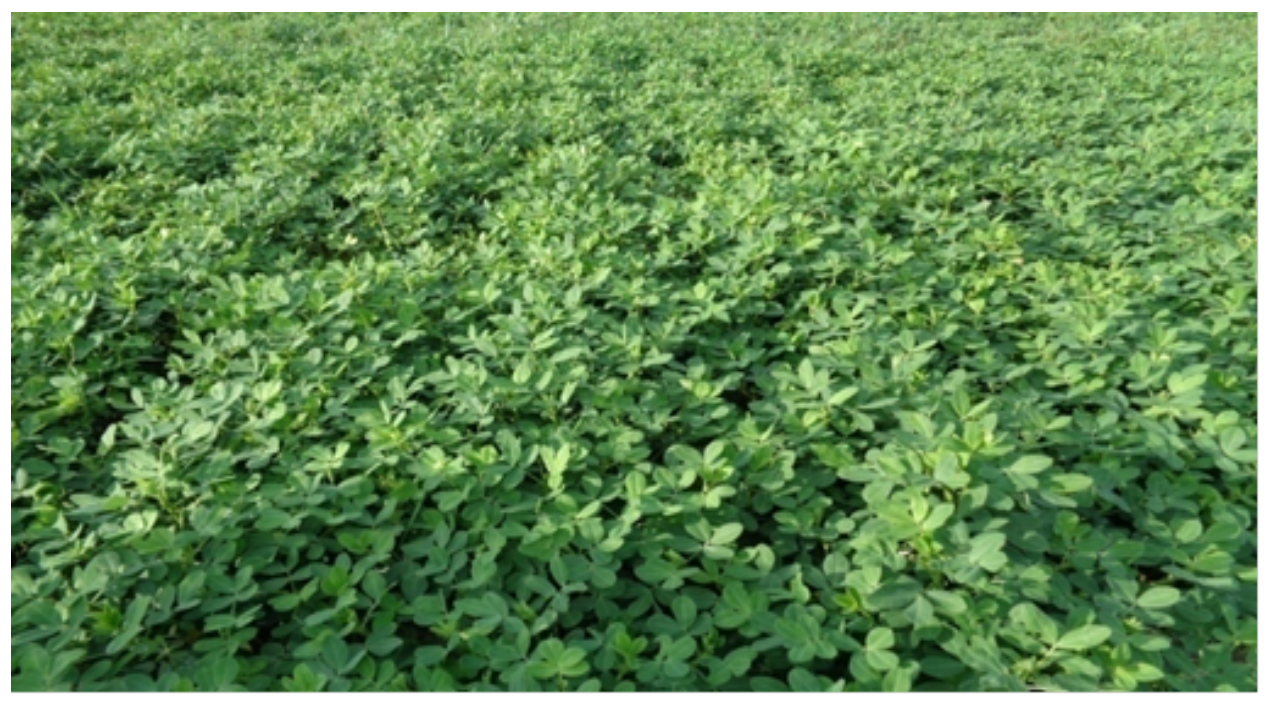

Photo 1 : Couverture quasi parfaite du sol par la culture d'arachide bien installée.

\section{Fertilisation}

N'apporter que du super phosphate triple à la dose de 100 à $125 \mathrm{~kg}$ ha $^{-1}$ à l'arachide au semis pour induire une plus grande efficacité de fixation symbiotique de l'azote

\section{Récolte et activités post récolte}

\section{Récolte de l'arachide}

Elle intervient à pleine maturité, quand plus de $90 \%$ des feuilles jaunissent. Arracher les plantes du sol. A l'aide d'un couteau, rechercher les gousses détachées de la plante et restées dans le sol.

\section{Protection des résidus de culture}

A la récolte, maintenir les fanes d'arachide sur la parcelle en vue de restituer au sol les éléments minéraux fixés dans les résidus de récolte. 
La principale contrainte réside dans la nécessité de protéger les fanes d'arachide contre le bétail en zone d'élevage et contre les feux de brousse. A cet effet, une technologie est à pratiquer. Les propositions d'actions pour la mise à échelle de la technologie consistent à encourager l'enclosure dans les zones d'élevage en ayant recours à des haies d'épineux et en sensibilisant les populations contre les feux de brousse.

L'agriculteur peut aussi, juste après la récolte, procéder à deux opérations qui consistent en un émiettement puis en un enfouissement à la daba des fanes ainsi émiettées. De cette manière, la restitution des éléments minéraux mobilisés au sein des fanes est totale quant à la fertilité du sol.

\section{CULTURE DE MAÏS}

\section{Semis}

Le maïs est semé à $0,80 \mathrm{~m}$ entre lignes et $0,50 \mathrm{~m}$ entre poquets. Déposer 3 grains par poquet. Le démariage qui a lieu 2 semaines après semis, s'effectue à 2 plants par poquet, quand le sol est humide.

\section{Fertilisation}

Sur un précédent d'arachide, les doses d'engrais nécessaires au maïs sont réduites de 1/4. Un apport de fumure sous forme de :

(i) NPK 15151561 à raison de $175 \mathrm{~kg}^{-h^{-1}}$ au stade 3 feuilles des plantules et au stade 6 feuilles, appliquer de l'urée à $46 \%$ de $\mathrm{N}$ à la dose de $75 \mathrm{~kg}$.ha-1 à 4 ou $5 \mathrm{~cm}$ du poquet ;

(ii) NPK 231005 à raison de $175 \mathrm{~kg}^{-h^{-1}}$ au stade 3 feuilles des plantules et appliquer la même formule NPK 231005 à la dose de $75 \mathrm{~kg}$.ha-1 au stade 6 feuilles à 4 ou $5 \mathrm{~cm}$ du poquet

\section{Sarclage}

Le premier doit intervenir plus tôt pour éviter que les mauvaises herbes ne concurrencent le maïs. Effectuer un sarclo-buttage après l'apport de l'urée ou du NPK 231005.

\section{Récolte du maïs}

La récolte du maïs intervient 3 mois après le semis, quand tous les spathes et feuilles jaunissent. Elle s'effectue en arrachant l'épi de la tige. Le rendement attendu dans ces conditions est d'environ 5 t.ha-1 $^{-1}$. 


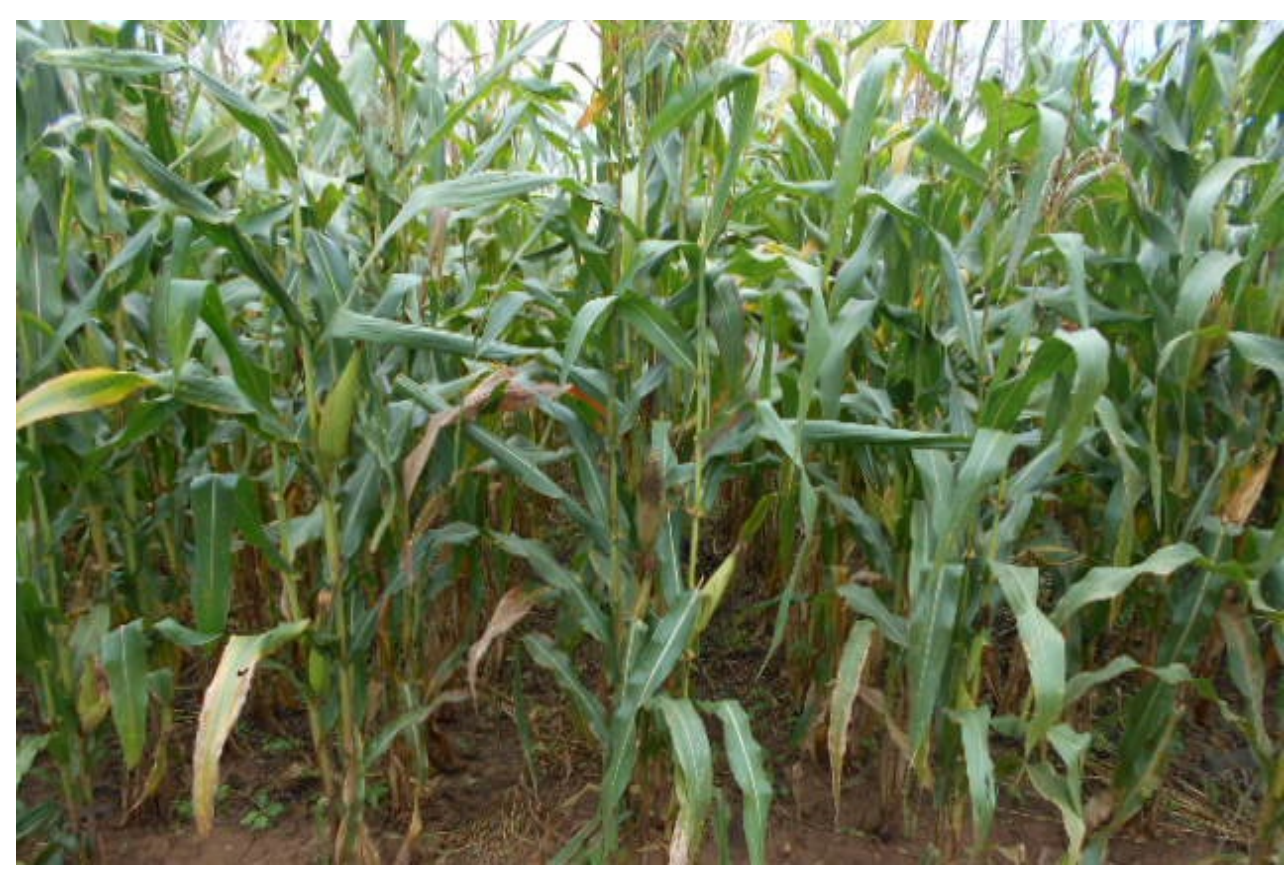

Photo 2 : Aspect végétatif du maïs à 80 JAS sur un précédent d'arachide et ayant bénéficié d'un apport de 175 kg.ha-1 de NPK 231005 et de 75 kg.ha-1 du même engrais.

\section{Traitement de semences}

Le traitement de la semence d'arachide à $12 \%$ et du maïs à $15 \%$ d'humidité est primordial pour la protection contre les insectes. Les produits utilisés sont le Marshall et le Thioral.

\section{RESULTATS}

Les rendements de l'arachide restent égaux à ceux observés souvent en culture pure. En revanche, l'on note une nette amélioration du rendement du maïs de l'ordre de 5 t.ha $^{-1}$ suite à un apport de $3 / 4$ de la dose d'engrais recommandée. Le précédent d'arachide induit donc une réduction de $25 \%$ des quantités d'engrais appliquées. Cela pourrait s'expliquer par l'amélioration de la fertilité du sol imputable aux fanes riches en éléments minéraux de la légumineuse. Leur décomposition sur le sol enrichit celui-ci.

\section{Calendrier cultural de la rotation arachide/maïs}

Tableau 2 : Calendrier cultural de la rotation arachide/maïs en zone de pluviométrie bimodale

\begin{tabular}{|l|l|l|l|l|l|l|l|l|l|l|}
\hline Opérations culturales & Mars & Avril & Mai & Juin & Juil. & Août & Sept. & Oct. & Nov. & Déc. \\
\hline 1. ARACHIDE & & & & & & & & & & \\
\hline Préparation terrain & & & & & & & & & & \\
\hline Semis & & & & & & & & & & \\
\hline Entretien & & & & & & & & & & \\
\hline Récolte & & & & & & & & & & \\
\hline 2. MAïS & & & & & & & & & & \\
\hline Semis & & & & & & & & & & \\
\hline Entretien & & & & & & & & & & \\
\hline Récolte & & & & & & & & & & \\
\hline
\end{tabular}

NB : En zone de pluviométrie monomodale, il est impossible de réaliser deux cycles culturaux par an. Dans ces conditions, la rotation arachide/maïs s'étale sur deux ans : année 1 , culture de l'arachide ; année 2 , culture du maïs. 


\section{Atouts spécifiques de la rotation arachide/maïs}

La culture de l'arachide entraine une couverture parfaite du sol (photo 1) si bien qu'il en résulte, un taux de réduction de l'enherbement de 105\% par rapport à la jachère conformément aux résultats obtenus à Ferkessédougou. En conséquence, la culture d'arachide permet de lutter efficacement contre les adventices et l'érosion du sol.

Cependant, les atouts de la technologie résident dans la réduction de $25 \%$ des quantités d'engrais apportées à la culture de maïs, la bonne productivité de cette céréale et le maintien du niveau de fertilité du sol. Les avantages visà-vis de la fertilité du sol, imputables au précédent d'arachide en comparaison avec la jachère naturelle à Ferkessédougou, sont connus (tableau 3). L'on note une amélioration significative de neuf paramètres du sol. En conséquence, le rendement en grains est nettement amélioré. En effet, la variété EV 8728 utilisée sur précédent d'arachide a permis d'obtenir, dans cette localité, un taux d'accroissement important de $39 \%$ du rendement en grains à $15 \%$ d'humidité en comparaison avec la jachère naturelle.

Tableau 3 : Améliorations de la fertilité du sol à l'actif du précédent d'arachide à Ferkessédougou en 2016

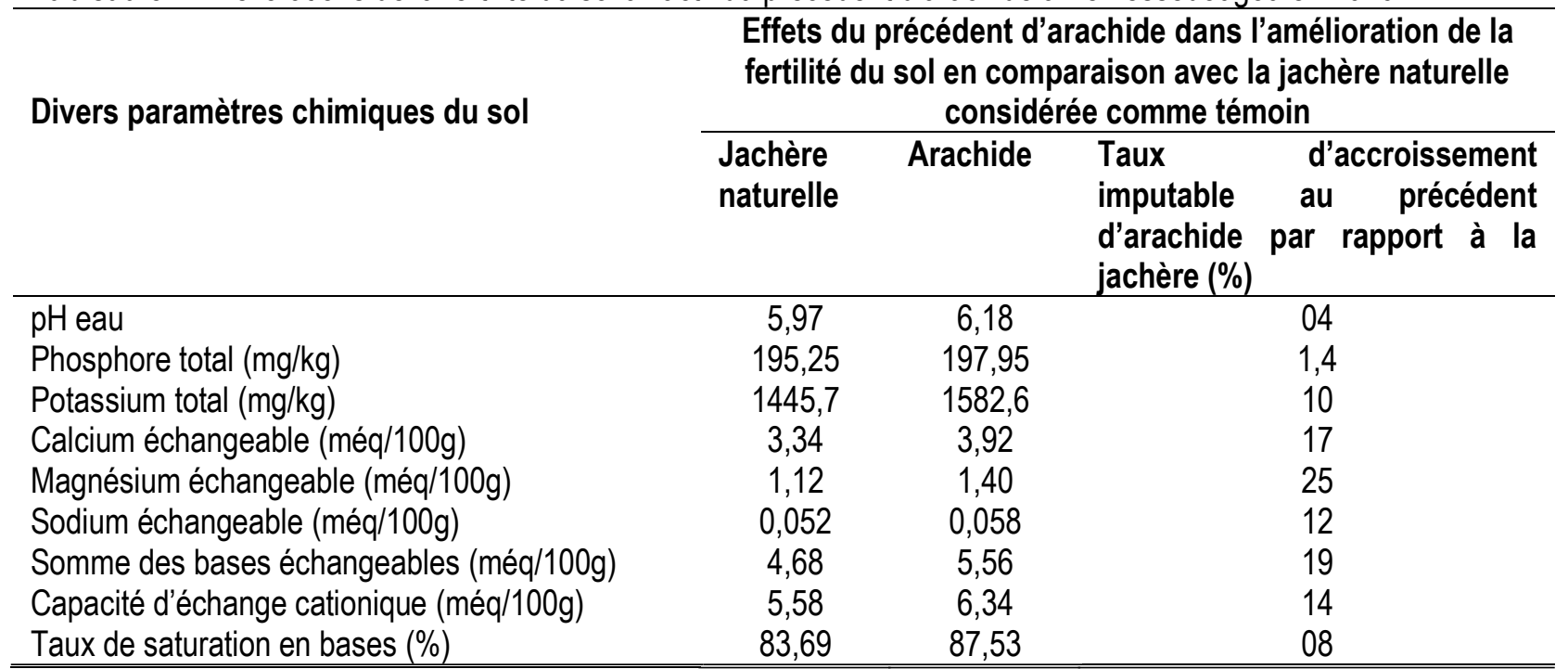

NB : Ces améliorations significatives qui évoluent de 1,4 à $25 \%$ notifient bien que l'arachide est une légumineuse propice à l'amélioration efficace de la fertilité chimique du sol et du rendement du maïs. 